\title{
Comportamento da cultivar BR-IPAGRO 44-guapo brilhante de feijoeiro em quatro populaçções de plantas na safrinha em Santa Maria-RS ${ }^{1}$
}

\author{
Behavior of cultivar BR-IPAGRO 44-guapo brilhante of common bean \\ in four plant populations in the latter season in Santa Maria-RS, Brazil
}

\begin{abstract}
Adilson Jauer $^{2}$ Luiz Marcelo Costa Dutra ${ }^{3}$ Orlando Antônio Lucca Filho ${ }^{4}$ Antônio Luis Santi ${ }^{2}$ Lucio Zabot ${ }^{5}$ Daniel Uhry ${ }^{6}$ Rafael Bonadiman $^{7}$ Gustavo Bellé $^{8}$ Alessandro Dala' Col Lúcio ${ }^{9}$
\end{abstract}

\section{RESUMO}

A cultivar Guapo Brilhante de feijoeiro comum, tipo II, foi cultivada durante a safrinha de $2001 \mathrm{em}$ Santa Maria-RS, com quatro populações de plantas (200, 300, 400 e 500 mil plantas $h^{-1}$ ). $O$ delineamento experimental utilizado foi o de blocos ao acaso, com quatro repetições. Foram avaliados o rendimento de grãos, os componentes do rendimento e algumas características morfológicas. A produtividade máxima estimada foi de $2684 \mathrm{~kg} \mathrm{ha}^{-1} \mathrm{com} \mathrm{a}$ população de plantas de 337 mil plantas $h^{-1}$, demonstrando que, com práticas culturais adequadas, na safrinha, é possível produzir quase três vezes acima da média de produtividade do feijoeiro comum do Rio Grande do Sul da década de 90. O aumento da população de planta aumentou a altura de inserção do primeiro legume, a altura de inserção da base do primeiro legume e reduziu o número de entrenós. A partir de $400 \mathrm{mil}$ plantas $h \mathrm{a}^{-1}$, as alturas de inserção do primeiro legume e da base do primeiro legume ajustam-se ao necessário para a colheita mecanizada, ainda que com perdas potenciais.

Palavras-chave: Phaseolus vulgaris L.,tipo II, feijão, população de plantas.

\section{ABSTRACT}

The common bean cultivar Guapo Brilhante, type II, was grown during the latter season of 2001 in Santa Maria-
RS, Brazil, in four plant populations (200, 300, 400, and 500 thousand plants $\left.\mathrm{ha}^{-1}\right)$. The experiment design was randomized blocks with four replications. The grain yield, yield components and some morphological traits were evaluated. The highest estimated yield was $2684 \mathrm{~kg} \mathrm{ha}^{-1}$ with 337 thousand plants ha ${ }^{1}$, demonstrating that, with proper cultural practices, in the latter season, it is possible to produce almost three times more than the best production average of the State of Rio Grande do Sul, Brazil in the 90 decade. The increase in plant population increases the first pod height, first pod base height, and the number of internodes. With 400 thousand plants $h a^{-1}$ the first pod height and the first pod base height are enough to mechanic harvesting, but with potential losses.

Key words: Phaseolus vulgaris $L$., plant populations, yield components, type II, beans.

\section{INTRODUÇÃO}

A cultura do feijoeiro comum (Phaseolus vulgaris L.), no Rio Grande do Sul, apresenta duas épocas de cultivo: a primeira, semeada de agosto a outubro, e chamada de safra; a segunda, semeada de janeiro a fevereiro, é chamada de safrinha, sendo que entre ambas existem diferenças climáticas sensíveis no

\footnotetext{
${ }^{1}$ Parte da dissertação de Mestrado do primeiro autor, como requisito parcial para obtenção do título de Mestre em Agronomia 900, Santa Maria, RS.E-mail: marcelo@ccr.ufsm.br Autor para correspondência.

${ }^{4}$ Professor Adjunto, Doutor, Departamento de Fitotecnia, Universidade Federal de Pelotas (UFPel).

${ }_{5}$ Aluno do curso de Agronomia, UFSM, Bolsista CNPq.

${ }^{6}$ Aluno do Cólégio Agrícola de Santa Maria,UFSM.

${ }^{7}$ Aluno do curso de Agronomia-UFSM, bolsista FIPE.

${ }^{8}$ Aluno do curso de Agronomia, UFSM.

${ }^{9}$ Engenheiro Agrônomo, Doutor, Professor Adjunto, Departamento de Fitotecnia, UFSM.
}

${ }^{1}$ Engenheiro Agrônomo, Doutor, Professor Adjunto, Departamento de Fitotecnia, Universidade Federal de Santa Maria (UFSM)

${ }^{2}$ Engenheiro Agrônomo, Aluno do Curso de Pós-graduação em Agronomia, UFSM, Bolsista CAPES, e-mail: ajauer@zipmail.com.br

${ }^{3}$ Engenheiro Agrônomo, Doutor, Professor Adjunto, Departamento de Fitotecnia, Universidade Federal de Santa Maria, 97119- 
que se refere à temperatura do ar e do solo e à disponibilidade hídrica.

A safrinha não tem merecido atenção da pesquisa, acarretando ao produtor rendimentos menores nesta época do que os obtidos na safra. Isso decorre do fato de que o pacote tecnológico recomendado para a safrinha foi desenvolvido, quase totalmente, sobre dados obtidos na safra. Uma das práticas que isoladamente mais condiciona o rendimento é a população de plantas, pela alteração que proporciona no microclima, na disponibilidade de luz, nutrientes e água, além de afetar as relações intraespecíficas.

Além disso, desde meados da década de 80, as pesquisas com arranjo de plantas em feijoeiro praticamente cessaram. Desta época até hoje, através do melhoramento, houve uma evolução nas cultivares de feijoeiro, sendo que os atuais materiais possibilitam rendimentos duas a três vezes superiores aos de 20 anos atrás, o que também justifica repensar o pacote para a safrinha, pois este aumento de capacidade produtiva poderá requerer condições de cultivo diferentes daquelas anteriormente utilizadas para poder expressar o máximo do seu potencial.

Dentro da espécie Phaseolus vulgaris L., as plantas pertencentes ao tipo II apresentam hábito de crescimento indeterminado, haste principal com tendência de crescimento vertical, ramos laterais não numerosos e geralmente curtos, os quais conferem à planta um aspecto arbustivo. Ainda pode ser constatada a presença de guias curtas ou longas, porém não necessitando de tutoramento. Como todas as plantas indeterminadas, as mesmas continuam crescendo mesmo durante a floração. Variedades classificadas como plantas do tipo II apresentam satisfatório potencial produtivo e adequada capacidade de compensação, quando da redução do estande (NETO \& FANCELLI, 2000).

A cultivar Rio Tibagi, tipo II, nas populações de 120, 240 e 360 mil plantas ha ${ }^{-1}$ não apresentou diferenças significativas devido aos tratamentos (BERGAMASCHI et al., 1975). Entretanto os pesquisadores comentaram a nítida tendência de diminuição no rendimento quando a população aumentou de 360 para 480 mil plantas ha ${ }^{-1}$.

Por outro lado, a cultivar Barriga Verde, tipo II, apresentou aumento linear no rendimento de grãos e no número de legumes $\mathrm{m}^{-2}$, à medida que a população aumentou de 200 para 400 mil plantas ha ${ }^{-1}$, enquanto o número de legumes planta ${ }^{-1} \mathrm{e}$ o peso médio de 100 grãos apresentaram comportamento inverso, independente do espaçamento entrelinhas (GUIDOLIN et al., 1998).

Segundo THOMAZ (2000), que trabalhou com três cultivares de hábito de crescimento indeterminado (uma tipo II, duas tipo III), em cinco populações de plantas $(100,200,300,400$ e 500 mil plantas ha-1), na safrinha em Santa Maria, não se observou diferença significativa no rendimento. Este comportamento foi explicado pelo autor pelo fato de que, plantas indeterminadas, quando supridas adequadamente, mesmo em menores populações, mantém a produção por área idêntica a maiores populações, quando a produção individual das plantas aumenta suficientemente para obter rendimento satisfatório.

\section{MATERIAL E MÉTODOS}

O experimento foi conduzido na área do Departamento de Fitotecnia no Campus da Universidade Federal de Santa Maria, no município de Santa Maria, RS, região climática da Depressão Central, a uma altitude de $95 \mathrm{~m}$, latitude $29^{\circ} 42^{\prime}$ '24" S e longitude $53^{\circ} 48^{\prime} 42$ ' W.

O clima da região, segundo a classificação de KÖEPPEN (MORENO, 1961) é do tipo Cfa temperado chuvoso, com chuvas bem distribuídas ao longo do ano e subtropical do ponto de vista térmico. A temperatura normal do mês mais quente ocorre em janeiro $\left(24,6^{\circ} \mathrm{C}\right)$ e a do mês mais frio em junho $\left(12,9^{\circ} \mathrm{C}\right)$. A temperatura média das máximas é de $30,4^{\circ} \mathrm{C}$ (janeiro) e de $19,2^{\circ} \mathrm{C}$ (junho). A média das temperaturas mínimas do mês mais quente é $18,7{ }^{\circ} \mathrm{C}$, em dezembro, e $9,3^{\circ} \mathrm{C}$ a do mês mais frio, em junho (BRASIL, 1992).

$\mathrm{O}$ solo pertence à unidade de mapeamento São Pedro, sendo classificado no Sistema Brasileiro de Classificação de Solos (EMBRAPA, 1999) como ARGISSOLO VERMELHO Distrófico arénico.

A correção do solo e a adubação da área foram feitas de acordo com os resultados da análise de solo, em concordância com as recomendações da ROLAS (1994) para a cultura do feijoeiro, utilizando 4,8 toneladas ha-1 de calcário PRNT $100 \%$ e $450 \mathrm{~kg} \mathrm{ha}^{-1} \mathrm{da}$ formulação 5-20-20 na semeadura. O calcário foi aplicado quatro meses antes da semeadura.

A cultivar utilizada foi a Guapo Brilhante, nas densidades de semeadura de 200, 300, 400 e 500 mil plantas ha- $\mathrm{h}^{-1}$ espaçadas de $0,40 \mathrm{~m}$ entre linhas.

$\mathrm{O}$ delineamento experimental utilizado foi o de blocos ao acaso com quatro repetições. As parcelas foram constituídas de oito linhas com $8,0 \mathrm{~m}$ de comprimento, espaçadas $0,40 \mathrm{~m}$, com área total de $25,6 \mathrm{~m}^{2}$. A área útil constituiu-se de duas linhas descontando $1,0 \mathrm{~m}$ nas extremidades como bordadura, perfazendo uma área de $4,8 \mathrm{~m}^{2}$.

Para a semeadura, foi feita a contagem manual das sementes para cada linha com sua respectiva densidade de semeadura corrigida para o 
poder germinativo de $100 \%$ mais $5 \%$, para obter a densidade desejada, sendo a semeadura realizada dia 21 de fevereiro de 2001. A emergência foi considerada quando, aproximadamente, $50 \%$ das plântulas haviam emergido, aos seis dias após a semeadura. Aos 17 dias após a emergência, foi realizada adubação de cobertura com $80 \mathrm{~kg} \mathrm{ha}^{-1}$ de nitrogênio na forma de uréia.

Foram executadas as práticas culturais recomendadas para obtenção do controle de insetos, moléstias e plantas daninhas, garantindo que o experimento ocorresse sem nenhuma interferência desses fatores.

Em cada parcela, por ocasião da colheita $(90$ dias após a emergência), foi amostrado 0,50 metro da área útil para as seguintes determinações: altura da base do primeiro legume ao solo , altura da inserção do primeiro legume ao solo, estatura de plantas, número de grãos legume ${ }^{-1}$, número de legumes planta ${ }^{-1}$, número de legumes. $\mathrm{m}^{-2}$, número de nós da haste principal planta $^{-1}$, número de ramos $\mathrm{m}^{-2}$ e peso de 100 grãos.

Para análise do rendimento de grão, as plantas da área útil foram arrancadas e posteriormente trilhadas em trilhadeira estacionária. Os grãos limpos foram pesados e feita a determinação do teor de umidade, após então, calculado o rendimento em $\mathrm{kg}$ $\mathrm{ha}^{-1}$, com correção do peso para a umidade de $13 \%$.

A análise estatística dos dados foi realizada através de análise da variância e teste de hipóteses para verificar a significância da interação e dos efeitos principais (STORCK \& LOPES, 1998), com auxílio do programa estatístico SOC (EMBRAPA, 1986).

Os dados de temperatura, precipitação pluvial e evapotranspiração foram obtidos junto à estação meteorológica do Departamento de Fitotecnia, localizada no Campus da Universidade Federal de Santa Maria.

\section{RESULTADOS E DISCUSSÃO}

O rendimento de grãos (Figura 1A) apresentou comportamento quadrático, sendo o valor máximo de $2684 \mathrm{~kg} \mathrm{ha}^{-1}$ estimado com 337 mil planta ha${ }^{1}$, alcançando desempenho 2,9 vezes maior do que a melhor média de produtividade do Rio Grande do Sul na década de 90. A atual recomendação para as cultivares do tipo II é de 200 a 250 mil plantas ha ${ }^{-1}$ (RECOMENDAÇÕES TÉCNICAS PARA A CULTURA DO FEIJÃO-2000). LEMOS et al. (1993) e ALMEIDA \& SANGOI (1994), com populações de até 300 mil plantas $\mathrm{ha}^{-1}$ de cultivares de feijoeiro do tipo II não observaram diferenças significativas no rendimento. BERGAMASCHI et al. (1977) não observaram diferença

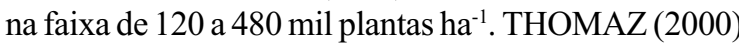

com a cultivar IAPAR 44, entre 100 e 500 mil plantas ha', em Santa Maria, na safrinha, também não observou efeito dos tratamentos sobre o rendimento. As diferenças do presente trabalho podem ser explicadas pela interação cultivar X ano X população de plantas, interação esta já detectada por CROTHERS \& WESTERMANN (1976) para cultivares do tipo II.

As condições climáticas durante o período vegetativo da cultura apresentaram uma temperatura média de $25,4^{\circ} \mathrm{C}$, precipitação média de $4,17 \mathrm{~mm} \mathrm{dia}^{-1} \mathrm{e}$ evapotranspiração média de $3,21 \mathrm{~mm} \mathrm{dia}^{-1}$. Para todo o ciclo da cultura, a temperatura média foi de $21,5^{\circ} \mathrm{C}$, precipitação média de $5,12 \mathrm{~mm} \mathrm{dia}^{-1}$ e evapotranspiração de 2,30 $\mathrm{mm} \mathrm{dia}^{-1}$ apresentando um saldo de 2,82 $\mathrm{mm}$ dia${ }^{1}$. Isto mostra que as condições climáticas para o desenvolvimento da cultura foram adequadas, mesmo com um excesso de umidade, o qual não causou limitação devido à boa drenagem do solo.

O número de legumes.planta ${ }^{-1}$ (Figura 1B) apresentou comportamento quadrático, sendo o maior valor com 200 mil plantas ha $^{-1}\left(18,0\right.$ legumes planta $\left.^{-1}\right) \mathrm{e}$ o menor valor, 8,0 vagens plantas ${ }^{-1}$ com 470 mil plantas ha $^{-1}$. AGUDELO et al. (1972) mencionam que este comportamento é normal para plantas deste hábito de crescimento, sendo confirmado por BERGAMASCHI \& WESTPHALEN (1976), BERGAMASCHI (1977), ALCÂNTARA et al. (1991), LEMOS et al. (1993), ARF et al. (1997), GUIDOLIN et al. (1998) e THOMAZ (2000).

$\mathrm{O}$ número de legumes $\mathrm{m}^{-2}$ (figura $1 \mathrm{C}$ ) apresentou comportamento linear decrescente, sendo o maior valor com 200 mil plantas hä ${ }^{-1}$ (400 legumes $\mathrm{m}^{-2}$ ) e o menor valor com 500 mil plantas ha $^{-1}$ (293,3 legumes $\mathrm{m}^{-2}$ ). BERGAMASCHI et al. (1977) e GUIDOLIN et al. (1998) mencionam que o número de legumes $\mathrm{m}^{-2}$ aumentou à medida que aumentou densidade de semeadura, diferentemente do observado neste experimento, em que a redução do número de legumes planta $^{-1}$ não foi compensado pelo acréscimo do número de plantas por unidade de área. Isso se explica pelas condições climáticas favoráveis para desenvolvimento das plantas, afetando o crescimento vegetativo, e elevando a competição intraespecífica, a ponto de reduzir o número de legumes planta ${ }^{-1}$ em níveis menores aos esperados pelos dados da literatura.

$\mathrm{O}$ número de grãos legume ${ }^{-1}$ não variou, apresentando valor médio de 4,6 grãos legume ${ }^{-1}$. O mesmo comportamento foi observado por AGUDELO et al. (1972), LUCAS \& MILBOURN (1976), LEMOS et al. (1993), ARF et al. (1996) e BASTYDAS \& CAMACHO apud THOMAZ (2000) os quais mencionam que as variações nesta característica são muito mais influenciadas pelo ambiente do que pela população de plantas.

O peso de 100 grãos também não apresentou diferença significativa, sendo a média do experi-

Ciência Rural, v. 33, n. 2, mar-abr, 2003. 


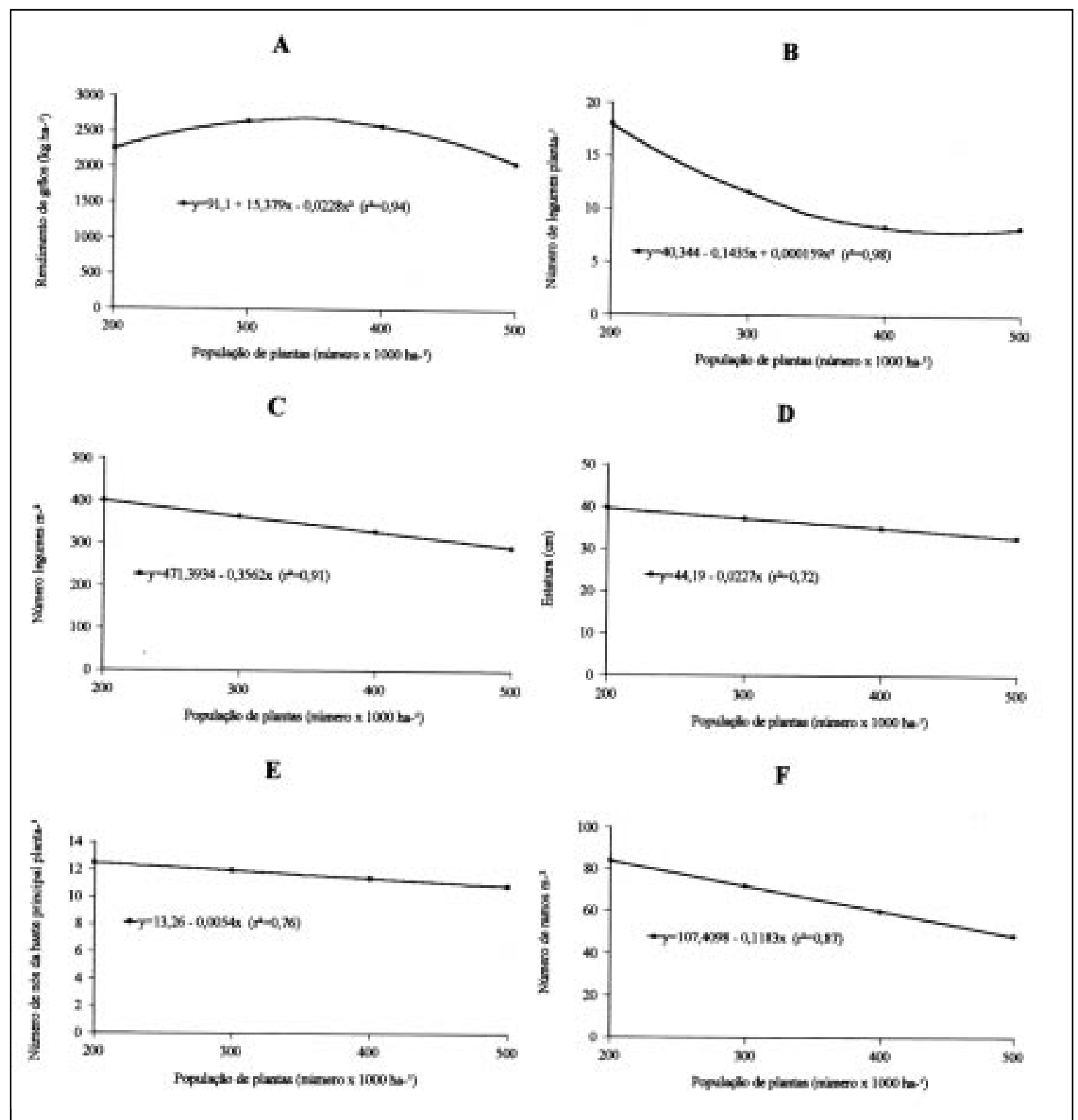

Figura 1 - Rendimento de grãos $\left(\mathrm{kg} \mathrm{ha}^{-1}\right)(\mathbf{A})$, número de legumes planta ${ }^{-1}(\mathbf{B})$, número de legumes $\mathrm{m}^{-2}(\mathbf{C})$, estatura de planta $(\mathbf{D})$, número de nós da haste principal planta ${ }^{-1}(\mathbf{E})$ e número de ramos $\mathrm{m}^{-2}(\mathbf{F})$ da cultivar de feijão Guapo Brilhante, em quatro população de plantas.ha ${ }^{-1}$, cultivada na safrinha de 2001, em Santa Maria-RS.

mento de 21,75 g. As respostas encontradas na literatura para esta característica são variáveis. THOMAZ (2001) também não observou diferença nesta característica em função da população de plantas. Já CROTHERS \& WESTERMANN (1976)e GUIDOLIN et al. (1998) verificaram que o peso de 100 grãos decresceu linearmente à medida em que a população aumentou.
Nenhum dos componentes seguiu a mesma tendência do rendimento. Os resultados do rendimento explicam-se pelas variações não significativas de grãos legume ${ }^{-1}$ e peso de 100 grãos quando multiplicados entre si e pelo número de legumes planta ${ }^{-1}$, resultando no rendimento observado.

A estatura de planta (Figura 1D), número de nós da haste principal (Figura 1E) e de ramos $\mathrm{m}^{-2}$ (Figu-

Ciência Rural, v. 33, n. 2, mar-abr, 2003. 
A

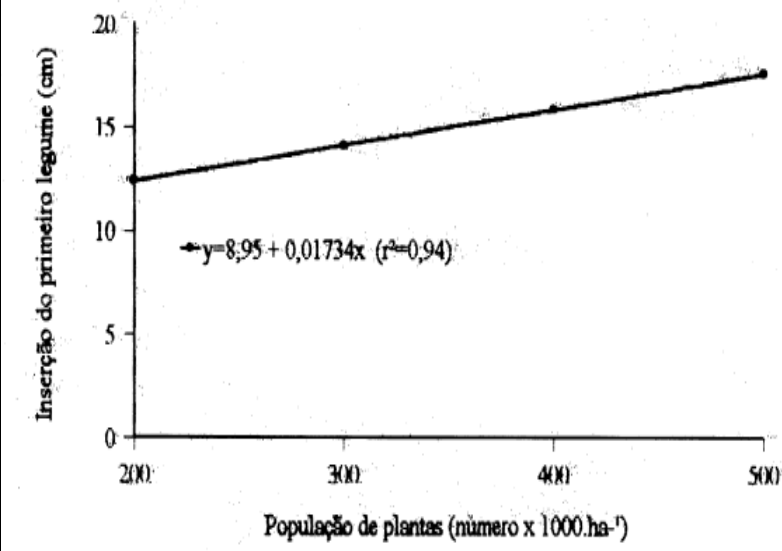

B

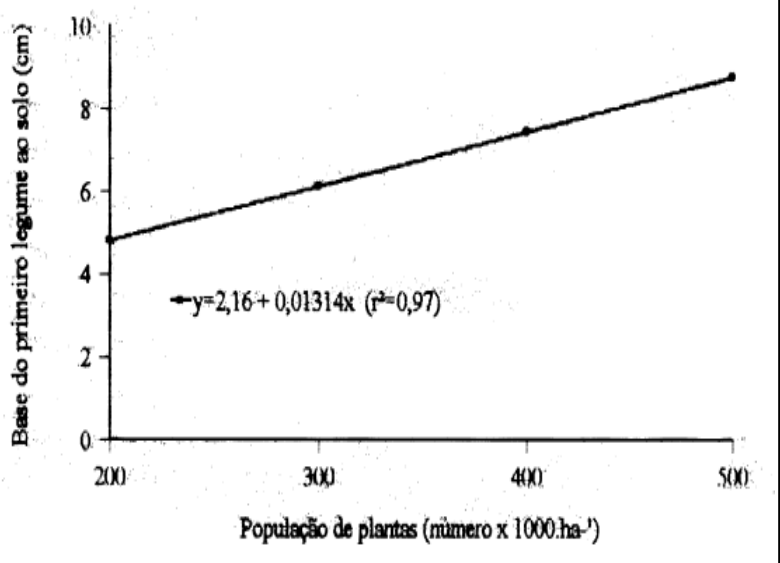

Figura 2 - Altura da inserção do primeiro legume (A) e da base do primeiro legume (B) da cultivar de feijão Guapo Brilhante, em quatro população de plantas ha ${ }^{-1}$, cultivada na safrinha de 2001, em Santa Maria-RS.

ra 1F) apresentaram comportamento linear decrescente com aumento da população de plantas, com os maiores valores na densidade de 200 mil plantas ha ${ }^{-1}$, res-

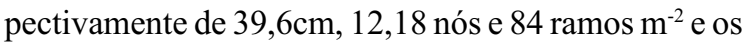
menores valores na densidade de 500 mil plantas ha- ${ }^{-1}$ com valores respectivos de $37 \mathrm{~cm}, 10,6$ nós e 48 ramos $\mathrm{m}^{-2}$. Considerando que não houve variação no tamanho dos entrenós, as variações observadas na estatura de planta foram em função da redução do número de entrenós (valor médio de 3,18 cm). NIENHUIS \& SINGH (1985), ALCÂNTARA et al. (1991) e JADOSKI et al. (2000) também observaram redução na estatura de planta de feijoeiro com o aumento da população de plantas.

A altura de inserção do primeiro legume ao solo (Figura 2A) e da base do legume ao solo (Figura 2B) apresentaram comportamento linear crescente com aumento da densidade de semeadura. Com 400 mil plantas $\mathrm{ha}^{-1}$, a altura da inserção do primeiro legume ao solo foi de $16 \mathrm{~cm}$ e da base do primeiro legume ao solo de $7,5 \mathrm{~cm}$. Com estes valores, seria possível a colheita mecanizada. No entanto, foi observado para esta cultivar elevada prostração do caule e ramos, o que por certo prejudicaria este tipo de colheita ainda que os dados disponíveis não permitam inferir sobre o montante das perdas nestas condições de cultivo. O mesmo também foi observado por GUIDOLIN et al. (1998), HORN et al. (2000) e JADOSKI et al. (2000).

\section{CONCLUSÕES}

A melhor população de plantas para a cultivar de feijão BR IPAGRO-44 Guapo Brilhante de feijoeiro, na safrinha, em Santa Maria, é de 337 mil plantas ha' ${ }^{-1}$.

Com práticas culturais adequadas, incluindo população adequada de plantas, a safrinha apresenta potencial de cultivo.

O aumento da população de plantas aumenta a altura de inserção do primeiro legume, a altura de inserção da base do primeiro legume e reduz o número de entrenós.

A partir de 400 mil plantas ha $^{-1}$, as alturas de inserção do primeiro legume e da base do primeiro legume possibilitam a colheita mecânica, ainda que com perdas.

\section{REFERÊNCIAS BIBLIOGRÁFICAS}

AGUDELO, D.O; HERNANDEZ L.A.; BASTIDAS, R.G. Efecto de la densidade de plobacion en el rendimiento y otras caracteristicas agronomicas del frijol (Phaseolus vulgaris L.). de crescimiento voluble y arbustivo. Acta agronomica, Palmira, v.22, p. 39-50, 1972.

ALCÂNTARA, J.P.et al. Avaliação de cultivares de feijoeiro (Phaseolus vulgaris L.) em diferentes densidades de semeadura e condições de ambiente. Ciência e Prática, Lavras, v. 15, p.331-428,1991.

ALMEIDA, M.L. de.; SANGOI, L. Manejo de cultivares de feijão de diferentes hábitos de crescimento no planalto catarinense. Rendimento de grãos. Ciência Rural, Santa Maria, v.24, n.3, p.513-517, 1994.

ARF, O. et al. Efeito de diferentes espaçamentos e densidades de semeadura sobre o desenvolvimento do feijoeiro (Phaseolus vulgaris L.). Pesquisa Agropecuária Brasileira, Brasília, v.31, n.09, p.629-634, set, 1996.

ARF, O. et al. Efeito de diferentes espaçamentos e densidades

Ciência Rural, v. 33, n. 2, mar-abr, 2003. 
em feijoeiro (Phaseolus vulgaris L.) adubado de acordo com a área e a população de plantas. Científica, São Paulo, v.25, n.1, p.45-57, 1997.

BERGAMASCHI, H.; WESTPHALEN, S.L. Efeitos de regimes da umidade do solo em diferentes estádios de desenvolvimento e populações no rendimento do feijoeiro (Phaseolus vulgaris L.). In: REUNIÃO TÉCNICA ANUAL DO FEIJÃO 12., 1975, Porto Alegre. Ata... Porto Alegre : IPAGRO, 1975. p.24-55.

BERGAMASCHI, H.; WESTPHALEN, S.L. Efeitos de regimes de umidade do solo e diferentes estádios de desenvolvimento e populações no rendimento do feijoeiro (Phaseolus vulgaris L.). In: REUNIÃO TÉCNICA ANUAL DO FEIJÃO 13., 1976, Porto Alegre. Ata... Porto alegre : IPAGRO, 1976. p. 36-50.

BERGAMASCHI, H.; WESTPHALEN,S.L.; MATZENAUER, R. Efeitos de regimes de umidade do solo em diferentes estádios de desenvolvimento e populações no rendimento do feijoeiro (Phaseolus vulgaris L.). In: REUNIÃO TÉCNICA ANUAL DO FEIJÃO 14., 1977, Porto Alegre. Ata... Porto Alegre : IPAGRO, 1977. p.22-28.

BRASIL. Ministério da Agricultura e do Abastecimento. Instituto Nacional de Meteorologia - INMET. Oitavo Distrito de Meteorologia $-8^{0}$ DISME. Normais climatológicas obtidas com dados do período 1961-1990. Brasília. 1992. 84p.

COMISSÃO ESTADUAL DE PESQUISA DE FEIJÃO. Recomendações técnicas para o cultivo no Rio Grande do Sul. Santa Maria : Pallotti, 2000. 80 p.: il., tabs. (Comissão Estadual de Pesquisa de Feijão; coordenador Ricardo Silveira Balardin).

CROTHERS, S.E.; WESTERMANN, D.T. Plant population effects on the seed yield of Phaseolus vulgaris L. Agronomy Journal, v. 68, nov-dez, p.958-960, 1976.

DOURADO NETO, D. Produção de feijão. (Durval Dourado Neto, Antonio Luiz Fancelli). Guaíba : Agropecuária, 2000. $385 \mathrm{p}$.

EMBRAPA. Centro Nacional de Pesquisa de Solos (Rio de Janeiro, RJ). Sistema Brasileiro de Classificação de Solos. Brasília : EMBRAPA Produção de Informações: RJ:
EMBRAPA Solos, 1999. XXVI, 412p.

GUIDOLIN, A.F. et al. Efeito do arranjo e da população de plantas sobre o crescimento do feijão em semeadura tardia. Ciência Rural, Santa Maria, v.28, n.4, p.547-551, 1998.

HORN, F.L. et al. Avaliação de espaçamento e populações de plantas de feijão visando à colheita mecanizada direta. Pesquisa Agropecuária Brasileira, Brasília, v.35, n.1, p.4146, jan, 2000.

JADOSKI, S.O. et al. População de plantas e espaçamento entre linhas do feijoeiro irrigado. I: Comportamento morfológico das plantas. Ciência Rural, Santa Maria, v.30, n.4, p.559-565, 2000.

LEMOS, L.B.; FORNASIERI FILHO, D.; PEDROSO, P. A.C. Comportamento de cultivares de feijoeiro com distintos hábitos de crescimento, em diferentes populações, em semeadura de inverno. Científica, São Paulo, v.21, n.1, p. 113-120, 1993.

LUCAS, E.O. et al. The effect of density of planting on the growth of two Phaseolus vulgaris varieties in England. Journal Agricultural Science, Cambridge, v.87, n.1, p.89-99, 1976.

NIENHUIS, J.; SINGH, S.P. Effects of plant density on yield and architectural traits in dry beans. Crop Science, Madison, v.25, n.4, p.579-584, Jul-ago, 1985.

MORENO, J.A. Clima do Rio Grande do Sul. Porto Alegre: Secretaria da Agricultura, Diretoria de Terras e Colonização, Secção de Geografia, 1961. 46p.

ROLAS. Recomendações de adubação e de calagem para os estados do Rio Grande do Sul e de Santa Catarina. 3 ed. Passo Fundo : SBCS-Núcleo Regional Sul, 1994. 224p.

STORCK, L.; LOPES, S.J. Experimentação II. 2.ed. Santa Maria : UFSM, CCR, Departamento de Fitotecnia, 1998. 205p.

THOMAZ. L.F. População de plantas para feijoeiro comum (Phaseolus vulgaris $L$ ) na safrinha em Santa MariaRS. 2001. 129f. Dissertação (Mestrado em Agronomia) Curso de Pós-graduação em Agronomia, Universidade Federal de Santa Maria. 